\title{
Socioeconomic inequalities in stillbirth rates in Europe: measuring the gap using routine data from the Euro-Peristat Project
}

Jennifer Zeitlin ${ }^{1 *}$, Laust Mortensen², Caroline Prunet ${ }^{1}$, Alison Macfarlane ${ }^{3}$, Ashna D. Hindori-Mohangoo ${ }^{4}$, Mika Gissler ${ }^{5}$, Katarzyna Szamotulska ${ }^{6}$, Karin van der Pal ${ }^{4}$, Francisco Bolumar ${ }^{7}$, Anne-Marie Nybo Andersen², Helga Sól Ólafsdóttir ${ }^{8}$, Wei-Hong Zhang ${ }^{9}$, Béatrice Blondel ${ }^{1}$, Sophie Alexander ${ }^{9}$ and Euro-Peristat Scientific Committee

\begin{abstract}
Background: Previous studies have shown that socioeconomic position is inversely associated with stillbirth risk, but the impact on national rates in Europe is not known. We aimed to assess the magnitude of social inequalities in stillbirth rates in European countries using indicators generated from routine monitoring systems.

Methods: Aggregated data on the number of stillbirths and live births for the year 2010 were collected for three socioeconomic indicators (mothers' educational level, mothers' and fathers' occupational group) from 29 European countries participating in the Euro-Peristat project. Educational categories were coded using the International Standard Classification of Education (ISCED) and analysed as: primary/lower secondary, upper secondary and postsecondary. Parents' occupations were grouped using International Standard Classification of Occupations (ISCO08) major groups and then coded into 4 categories: No occupation or student, Skilled/ unskilled workers, Technicians/clerical/service occupations and Managers/professionals. We calculated risk ratios (RR) for stillbirth by each occupational group as well as the percentage population attributable risks using the most advantaged category as the reference (post-secondary education and professional/managerial occupations).

Results: Data on stillbirth rates by mothers' education were available in 19 countries and by mothers' and fathers' occupations in 13 countries. In countries with these data, the median RR of stillbirth for women with primary and lower secondary education compared to women with postsecondary education was 1.9 (interquartile range (IQR): 1.5 to 2.4 ) and 1.4 (IQR: 1.2 to 1.6), respectively. For mothers' occupations, the median RR comparing outcomes among manual workers with managers and professionals was 1.6 (IQR: 1.0-2.1) whereas for fathers' occupations, the median RR was 1.4 (IQR: 1.2-1.8). When applied to the entire set of countries with data about mothers' education, 1606 out of 6337 stillbirths (25\%) would not have occurred if stillbirth rates for all women were the same as for women with post-secondary education in their country.
\end{abstract}

Conclusions: Data on stillbirths and socioeconomic status from routine systems showed widespread and consistent socioeconomic inequalities in stillbirth rates in Europe. Further research is needed to better understand differences between countries in the magnitude of the socioeconomic gradient.

Keywords: Stillbirth, Socioeconomic factors, Europe, Health inequalities, Pregnancy, Mortality

\footnotetext{
* Correspondence: Jennifer.zeitlin@inserm.fr

${ }^{1}$ Inserm UMR 1153, Obstetrical, Perinatal and Pediatric Epidemiology

Research Team (Epopé), Center for Epidemiology and Statistics Sorbonne

Paris Cité, DHU Risks in pregnancy, Paris Descartes University, 53 avenue de

I'Observatoire, 75014 Paris, France

Full list of author information is available at the end of the article
} 


\section{Background}

Socioeconomic disadvantage, as measured by low levels of mothers' or fathers' education, occupational status or income, is associated with raised risks of stillbirth even in countries with universal insurance coverage and generous welfare provisions [1-6]. The hypothesised mechanisms are multiple and interrelated and include smoking, poor diet and other unhealthy behaviours, higher stress, less social support and depression, teenage motherhood, unplanned pregnancies, a higher prevalence of chronic health conditions, such as hypertension, diabetes, or obesity as well as poor access to antenatal care and receipt of suboptimal care [1, 7-9].

Many questions remain surrounding the causes of stillbirth and effective approaches to prevention. A high proportion of stillbirths, up to $30 \%$, remain unexplained even with complete clinical and autopsy records [10, 11]. Further, most stillbirths in high income countries occur before the onset of labour [12], providing fewer obvious possibilities for medical intervention than, for instance, cases of intra-partum, neonatal or infant death. Investigating the associations between socioeconomic position and stillbirth risk is an important component of efforts to advance knowledge about the aetiology and prevention of stillbirth.

A focus on social inequalities also emphasises the distal determinants of stillbirth risk which are accumulated over the life course and relate to parental health status, behaviours and knowledge preceding the pregnancy. Stillbirths may also perpetuate social differences in health by creating disease, in particular, maternal depression [13], and have been associated with long term risks for the mother [14]. Improving pregnancy outcomes by reducing stillbirths is therefore a component of broader national strategies to interrupt the transgenerational cycle of ill-health.

Comparing outcomes between social groups illustrates the poorer health associated with socioeconomic disadvantage and the outcomes that could be achieved in the absence of these inequalities. Having reliable indicators for measuring social inequalities in stillbirth enables target-setting for health policies, performance benchmarking and monitoring of trends over time. In this study, we sought to assess the magnitude of social inequalities in stillbirth rates in European countries using indicators generated from routine monitoring systems.

\section{Methods}

\section{Data sources}

Data come from the Euro-Peristat project, a collaboration between 26 member states of the European Union and Norway, Iceland and Switzerland, to assess perinatal health in Europe using a common set of 10 core and 20 recommended perinatal health indicators [15-17]. The indicators were developed following several Delphi consensus processes with multidisciplinary and geographically diverse panels of experts [18]. The aim was to select a succinct set of comparable indicators of mothers' and newborn babies' health and care which can be monitored routinely.

Data for the Euro-Peristat indicators were compiled using nationally aggregated population-based data from routine data collection systems for the year 2010, and have been described previously $[15,17,19]$. One scientific committee (SC) member per country was responsible for the oversight of data collection in their country, in collaboration with other data providers. When national data were not available, population-based regional data could be provided. In Belgium, data were provided separately for Brussels, Flanders and Wallonia and in the UK for England and Wales, Northern Ireland and Scotland. Slovakia provided core, but no recommended indicators. As these include the socioeconomic indicators, it could not be included in this study. In most countries, the data came from medical birth registers, civil registration and child health systems. Data in France and Cyprus came from routine surveys used to monitor perinatal health. In Cyprus the survey took place in 2007. In France, this source was used because of changes to definitions of stillbirth in 2007 meant that comparable indicators of stillbirths were not available from vital statistics in 2010 [20].

This study is based on aggregated routinely collected data, so ethics approval was not required.

\section{Socioeconomic factors}

Mothers' level of education was selected as the EuroPeristat marker of socioeconomic position, based on the Delphi process, which ranked indicators on experts' opinions about relevance as well as feasibility [18]. As an indicator for international comparisons, educational level has the advantage that UNESCO has established an international classification, the International Standard Classification of Education (ISCED), which has also been adopted by the EU Directorate General for Education and Culture [21]. However, because some European countries do not routinely collect data on education, updates to the Euro-Peristat indicator set in 2012 added SES indicators based on mothers' and fathers' occupational group.

The mothers' level of education indicator is defined as the highest level of education of women delivering live or stillborn babies. Data were requested on most detailed educational groupings in national systems and then recoded using the International Standard Classification of Education (ISCED - UNESCO, 1997), as follows: (0) primary not complete or none (1) primary complete, (2) lower secondary (up to 3 or 4 years), (3) higher 
secondary (up to 6 or 7 years), (4) post-secondary non tertiary (6 months to 2 years), (5) first stage of tertiary education (bachelor), (6) second stage of tertiary education (master, doctorate or more), (9) unknown. These categories were then collapsed into three groups: none, primary and lower secondary (0-2), higher secondary (3) and post-secondary (4-6). After the national classifications were recoded into the ISCED categories, they were sent to the SC members for validation.

Mother's and father's occupational class for parents of live or stillborn babies was defined using the International Standard Classification of Occupations (ISCO08) major groups: (1) managers (2) professionals (3) technicians and associate professionals (4) clerical support workers (5) service and sales workers (6) skilled agricultural, forestry and fishery workers (7) craft and related trades workers (8) plant and machine operators, and assemblers (9) elementary occupations (0) armed forces occupations (99) no profession (88) student. These occupational groups were then amalgamated into four categories: no occupation or student, skilled/unskilled workers, technicians/clerical/service occupations and managers/professionals. These were ordered from lowest to highest social status to be consistent with the coding of educational level. When countries could not provide these categories, they included those that they used. Ireland's classification is not based on the ISCO08, but was recoded into the four groups for our analysis. Occupations for England and Wales had been grouped into the eight class version of the National Statistics Socio-economics Classification (NSSec) [22] and subdivided into births registered jointly by both parents and those grouped by the mother alone. Students were included with"occupations inadequately described; occupations not classifiable for other reasons; never worked and long-term unemployed." This category was classified as unknown for the analysis. In Luxembourg, the classification is based on parent's employment (employed, student or unemployed) and these data were not used. In Slovenia, not all maternity units used the ISCO classification and these partial data were not used.

\section{Stillbirths}

Aggregated data were collected on the numbers of stillbirths and live births grouped by the three socioeconomic indicators: mother's level of education and mother's and father's occupational group. Euro-Peristat defines the stillbirth rate as the number of stillbirths at or after 22 completed weeks of gestation in a given year per 1000 live and stillbirths in the same year. If gestational age was not available, inclusion was determined by a birthweight of 500 grams or more. Not all countries could provide stillbirth data using this definition, as this depends on national registration criteria. In these cases, countries provided numbers of stillbirths in accordance with national definitions. Lower thresholds were $500 \mathrm{~g}$ in Germany, Austria, Poland, Slovenia, 24 weeks in Greece, Portugal and the United Kingdom (although Portugal and Scotland have voluntary notification at 22/ 23 weeks), 180 days in Spain and 500 grams or 24 weeks in Ireland. Another difference between countries is the way terminations of pregnancy (TOP) are recorded (either not at all, in a separate register or as stillbirths). In Slovenia and France, TOP were removed for this analysis (see Additional file 1: Table S1 for more details about inclusions).

\section{Analysis}

We described the availability of data on mother's level of education and parents' occupational groups for monitoring social differences in stillbirth and compared the distribution of these variables between the countries. Missing data were reported as a separate category and excluded from the analyses. We then calculated stillbirth rates for each educational and occupational category and corresponding risk ratios (RR) using the highest category as the reference (post-secondary education and professional/managerial occupations). To assess the potential margin for improvement, we calculated the percentage population attributable risks (\%PAR) and their $95 \%$ confidence intervals in each country using the best educated or highest occupational category as the reference. These were then applied to the number of stillbirths in our study to derive a predicted number of stillbirths if rates for all women were the same as the rates for the highest SES categories in their country. Results are also summarised as medians and intra-quartile ranges to provide general estimates and the spread across the counties. To assess the potential impact of missing data on our estimates, we calculated the association of the RR of the lowest social category to the reference group for each indicator with the proportion of missing data using Spearman correlation coefficients. Data were analysed with Stata SE13.0 and R 3.1.3 software.

\section{Results}

\section{Data availability and comparability}

As shown in Table 1, 23 out of 29 (79 \%) European countries provided stillbirth rates by at least one of the three SES indicators. Data on stillbirth rates by mother's level of education were available in 19 countries and by mother's and father's occupation in 13 countries. Nine countries provided stillbirth data grouped by both indicators.

All national educational classifications could be mapped into ISCED-97 codes, although countries provided varying levels of detail (from 4 to 13 categories) some did not record primary schooling only (Austria, Finland). Missing 
Table 1 Countries providing data and classifications used

\begin{tabular}{|c|c|c|c|c|c|c|c|}
\hline \multirow[b]{2}{*}{ Country } & \multicolumn{3}{|c|}{ Mother's level of education } & \multicolumn{2}{|c|}{ Mother's occupation } & \multicolumn{2}{|c|}{ Father's occupation } \\
\hline & Availability & Missing data (\%) & Number of class ${ }^{a}$ & Availability & Missing data (\%) & Availability & Missing data (\%) \\
\hline BE: Brussels & Yes & 8 & 8 & Yes & 1 & Yes & 8 \\
\hline BE: Flanders & Yes & 9 & 13 & Yes & 4 & Yes & 4 \\
\hline BE: Wallonia & Yes & 23 & 8 & Yes & 5 & Yes & 18 \\
\hline Czech Republic & Yes & 7 & 5 & - & - & - & - \\
\hline Denmark & Yes & 5 & 10 & - & - & - & - \\
\hline Germany & - & - & - & Yes & 22 & - & - \\
\hline Estonia & Yes & 0 & 7 & Yes & 25 & Yes & 21 \\
\hline Ireland & - & - & - & Yes & 5 & Yes & 26 \\
\hline Greece & - & - & - & - & - & - & - \\
\hline Spain & Yes & 5 & 11 & Yes & 5 & Yes & 8 \\
\hline France & Yes & 4 & 7 & Yes & 3 & Yes & 7 \\
\hline Italy & Yes & 3 & 6 & - & - & - & - \\
\hline Cyprus & Yes & 1 & 9 & - & - & - & - \\
\hline Latvia & Yes & 0 & 7 & - & - & - & - \\
\hline Lithuania & Yes & 0 & 6 & Yes & 0 & - & - \\
\hline Luxembourg & Yes & 4 & 8 & - & - & - & - \\
\hline Hungary & Yes & 1 & 6 & - & - & - & - \\
\hline Malta & Yes & 26 & 4 & - & - & - & - \\
\hline Netherlands & - & - & - & - & - & - & - \\
\hline Austria & Yes & 9 & 5 & - & - & - & - \\
\hline Poland & Yes & 0 & 8 & - & - & - & - \\
\hline Portugal & Yes & 2 & 9 & Yes & 13 & Yes & 10 \\
\hline Romania & - & - & - & Yes & 0 & - & - \\
\hline Slovenia & Yes & 15 & 12 & - & - & - & - \\
\hline Slovakia & - & - & - & - & - & - & - \\
\hline Finland & Yes & 14 & 7 & Yes & 27 & Yes & 13 \\
\hline Sweden & - & - & - & - & - & - & - \\
\hline United Kingdom & - & - & - & - & - & - & - \\
\hline UK: England and Wales & - & - & - & - & - & Yes & $12^{\mathrm{b}}$ \\
\hline UK: Scotland & - & - & - & - & - & - & - \\
\hline UK: Northern Ireland & - & - & - & - & - & - & - \\
\hline Iceland & - & - & - & - & - & - & - \\
\hline Norway & Yes & 0 & 7 & - & - & - & - \\
\hline Switzerland & - & - & - & - & - & - & - \\
\hline
\end{tabular}

anknown included

b'Inadequately described or not in employment, including students'

data ranged from 0 to $25 \%$, but was under $10 \%$ in the majority of countries. In general, missing data were more common for stillbirths than for live births. As shown in Table 2, there were marked variations in the distribution of mothers' level of education: primary and lower secondary (from 0.3 to $40 \%$ of mothers), higher secondary (from 20 to $60 \%$ of mothers) and post-secondary (from 20 to $60 \%$ of mothers).
For fathers' occupations, the skilled/unskilled worker category ranged from 22 to $47 \%$, but was between 35 and $45 \%$ in most countries (Table 3); the intermediate occupational category varied between 20 and $43 \%$ and the professionals and managers from 12 to $43 \%$. No occupation/student varied from 2 to $21 \%$, but in most countries was close to $5 \%$. It was unclear how father's occupation was coded if the father was not named on 
Table 2 Percentage distribution of mother's levels of education and stillbirth rates by educational level

\begin{tabular}{|c|c|c|c|c|c|c|c|c|c|}
\hline \multirow{3}{*}{ Country } & \multirow{3}{*}{$\begin{array}{l}\text { Total } \\
\text { Births } \\
\text { N } \\
\text { (all stated) }\end{array}$} & \multicolumn{3}{|c|}{ Distribution of births } & \multirow[b]{2}{*}{$\begin{array}{l}\text { Total } \\
\text { Stillbirths } \\
\text { (SB) }\end{array}$} & \multicolumn{4}{|c|}{ Stillbirth rates } \\
\hline & & $\begin{array}{l}\text { Primary and } \\
\text { lower secondary }\end{array}$ & $\begin{array}{l}\text { Higher } \\
\text { secondary }\end{array}$ & $\begin{array}{l}\text { Post- } \\
\text { secondary }\end{array}$ & & $\begin{array}{l}\text { Overall } \\
\text { SB rate }\end{array}$ & $\begin{array}{l}\text { SB rate Primay and } \\
\text { lower secondary }\end{array}$ & $\begin{array}{l}\text { SB rate Higher } \\
\text { secondary }\end{array}$ & $\begin{array}{l}\text { SB rate Post- } \\
\text { secondary }\end{array}$ \\
\hline & & $\%$ & $\%$ & $\%$ & N & p 1000 & p 1000 & p 1000 & p 1000 \\
\hline Austria & 72069 & 16.9 & 46.1 & 37.0 & 227 & 3.1 & 4.9 & 3.3 & 2.1 \\
\hline BE: Brussels & 22965 & 22.4 & 37.1 & 40.5 & 44 & 1.9 & 1.9 & 2.6 & 1.3 \\
\hline BE: Flanders & 62438 & 12.2 & 39.3 & 48.5 & 179 & 2.9 & 3.8 & 3.6 & 2.0 \\
\hline BE: Wallonia & 29546 & 17.8 & 39.9 & 42.2 & 75 & 2.5 & 4.7 & 2.4 & 1.8 \\
\hline Cyprus & 8302 & 9.5 & 29.8 & 60.6 & 25 & 3.0 & 2.5 & 4.8 & 2.2 \\
\hline $\begin{array}{l}\text { Czech } \\
\text { Republic }\end{array}$ & 108843 & 10.9 & 42.9 & 46.2 & 191 & 1.8 & 3.8 & 1.6 & 1.5 \\
\hline Denmark & 58841 & 16.6 & 36.7 & 46.6 & 220 & 3.7 & 5.7 & 3.9 & 2.9 \\
\hline Estonia & 15613 & 14.2 & 46.2 & 39.6 & 61 & 3.9 & 7.2 & 4.0 & 2.6 \\
\hline Finland & 51775 & - & 46.2 & 53.8 & 152 & 2.9 & - & 3.3 & 2.6 \\
\hline France & 14060 & 28.3 & 19.9 & 51.8 & 61 & 4.3 & 6.0 & 5.0 & 3.2 \\
\hline Hungary & 89979 & 20.0 & 46.3 & 33.7 & 349 & 3.9 & 8.2 & 3.5 & 1.8 \\
\hline Italy & 529166 & 33.0 & 44.2 & 22.7 & 1388 & 2.6 & 3.2 & 2.4 & 2.2 \\
\hline Latvia & 19246 & 16.3 & 39.6 & 44.1 & 107 & 5.6 & 7.0 & 6.0 & 4.6 \\
\hline Lithuania & 30472 & 12.9 & 29.1 & 58.0 & 136 & 4.5 & 6.1 & 5.2 & 3.7 \\
\hline Luxembourg & 6082 & 21.8 & 30.9 & 47.4 & 29 & 4.8 & 5.3 & 4.8 & 4.5 \\
\hline Malta & 2987 & 0.3 & 63.9 & 35.8 & 11 & 3.7 & 0.0 & 4.2 & 2.8 \\
\hline Norway & 53705 & 18.7 & 29.0 & 52.3 & 162 & 3.0 & 3.8 & 3.2 & 2.7 \\
\hline Poland & 408878 & 8.8 & 49.7 & 41.6 & 1629 & 4.0 & 6.5 & 4.6 & 2.8 \\
\hline Portugal & 98618 & 18.1 & 51.2 & 30.7 & 227 & 2.3 & 3.3 & 2.5 & 1.4 \\
\hline Slovenia & 19074 & 17.3 & 46.0 & 36.7 & 74 & 3.9 & 4.5 & 3.4 & 4.1 \\
\hline Spain & 464657 & 38.3 & 28.4 & 33.2 & 990 & 2.1 & 2.8 & 1.8 & 1.6 \\
\hline
\end{tabular}

the birth registration, as there was no separate category in most classifications. Only two countries provided a category "Sole registration by mother" (England and Wales, France), but information about father's occupations were missing for some births in most countries, ranging from 3 to $26 \%$. The distribution of mothers' occupations varied much more widely between countries The percentage in the no occupation/student group ranged from 8 to $48 \%$ and the percentage in the unskilled/skilled worker group varied from 1 to $45 \%$. The proportions of professionals/managers varied from 0.2 to $40 \%$. In general, the proportion of missing data was higher for occupation than educational level.

\section{Stillbirth rates and risk ratios by socioeconomic classification}

Stillbirth rates ranged from approximately 2 to 5 per 1000 in participating countries. Absolute rates for the socioeconomic classifications are displayed in Tables 2 and 3, while Figs. 1, 2 and 3 show RR of all categories compared to the highest category, juxtaposed with the proportional size of the groups illustrated by the band at the bottom of each country-specific graph. For mother's level of education, the lowest rate was in the most highly educated group in all countries except for Slovenia. For the occupational classifications, relationships were less consistently monotonic and many RR were not significantly different from the reference category. However, countries mainly had the lowest stillbirth rate in the highest socioeconomic group, except Germany, Finland, Romania and Lithuania for mother's occupational group and Estonia, France, and Ireland for father's occupational group.

Compared to women with post-secondary education, women with primary and lower secondary education had a median RR of stillbirth of 1.9 (IQR: 1.5 to 2.4) in the 19 countries providing these data. For women with higher secondary education, the median RR was 1.4 (IQR: 1.2 to 1.6). For mother's occupational group, the median RR comparing outcomes among manual workers with managers and professionals was 
Table 3 Percentage distribution of mothers and fathers' occupations and stillbirth rates by occupational group

\begin{tabular}{|c|c|c|c|c|c|c|c|c|c|c|c|}
\hline \multirow[t]{2}{*}{ Country } & $\begin{array}{l}\text { Total } \\
\text { Births }\end{array}$ & $\begin{array}{l}\text { No occupation } \\
\text { or student }\end{array}$ & $\begin{array}{l}\text { Skilled/ } \\
\text { unskilled } \\
\text { workers }\end{array}$ & $\begin{array}{l}\text { Technicians/ } \\
\text { clerical/ service }\end{array}$ & $\begin{array}{l}\text { Managers/ } \\
\text { professionals }\end{array}$ & $\begin{array}{l}\text { Total } \\
\text { Stillbirths } \\
\text { (SB) }\end{array}$ & $\begin{array}{l}\text { Overall } \\
\text { SB rate }\end{array}$ & $\begin{array}{l}\text { SB rate No } \\
\text { occupation or } \\
\text { student }\end{array}$ & $\begin{array}{l}\text { SB rate Skilled/ } \\
\text { unskilled workers }\end{array}$ & $\begin{array}{l}\text { SB rate Technicians/ } \\
\text { clerical/ service }\end{array}$ & $\begin{array}{l}\text { SB rate Managers/ } \\
\text { professionals }\end{array}$ \\
\hline & $\begin{array}{l}\mathrm{N} \\
\text { (all stated) }\end{array}$ & $\%$ & $\%$ & $\%$ & $\%$ & $\mathrm{~N}$ & p 1000 & p 1000 & p 1000 & p 1000 & p 1000 \\
\hline \multicolumn{12}{|c|}{ Maternal occupation } \\
\hline BE: Brussels & 24432 & 46.6 & 7.4 & 42.2 & 3.8 & 127 & 5.2 & 6.1 & 5.0 & 4.5 & 2.1 \\
\hline BE: Flanders & 64790 & 17.8 & 15.3 & 60.9 & 6.0 & 229 & 3.5 & 5.3 & 4.7 & 2.9 & 1.3 \\
\hline BE: Wallonia & 35777 & 40.4 & 9.0 & 46.5 & 4.0 & 139 & 3.9 & 5.0 & 3.7 & 3.1 & 2.1 \\
\hline Estonia & 11731 & 7.5 & 9.6 & 42.9 & 40.0 & 44 & 3.8 & 3.4 & 6.2 & 4.0 & 3.0 \\
\hline Finland & 43734 & 11.8 & 12.4 & 53.7 & 22.1 & 128 & 2.9 & 2.9 & 2.2 & 3.1 & 2.8 \\
\hline France & 14239 & 14.5 & 17.2 & 55.9 & 12.4 & 86 & 6.0 & 5.8 & 9.0 & 5.7 & 4.0 \\
\hline Germany & 488041 & 34.0 & 45.1 & 17.0 & 3.9 & 1378 & 2.8 & 3.5 & 2.7 & 2.0 & 2.6 \\
\hline Ireland & 70528 & 26.4 & 5.4 & 37.8 & 30.3 & 319 & 4.5 & 5.6 & 5.5 & 4.5 & 3.5 \\
\hline Lithuania & 30568 & 29.0 & 8.8 & 26.5 & 35.6 & 137 & 4.5 & 5.6 & 3.7 & 3.5 & 4.5 \\
\hline Portugal & 87627 & 19.9 & 19.4 & 43.1 & 17.7 & 211 & 2.4 & 3.9 & 3.4 & 1.6 & 1.6 \\
\hline Romania & 199641 & 47.5 & 1.3 & 51.0 & 0.2 & 780 & 3.9 & 5.4 & 5.0 & 2.5 & 3.3 \\
\hline Slovenia & 7687 & 0.0 & 5.0 & 58.4 & 36.6 & 18 & 2.3 & 0.0 & 2.6 & 1.6 & 3.6 \\
\hline Spain & 465343 & 24.7 & 11.3 & 46.4 & 17.6 & 1305 & 2.8 & 3.7 & 3.4 & 2.4 & 2.4 \\
\hline \multicolumn{12}{|c|}{ Paternal occupation } \\
\hline BE: Brussels & 22976 & 20.9 & 22.4 & 43.1 & 13.6 & 106 & 4.6 & 7.9 & 3.7 & 4.3 & 1.9 \\
\hline BE: Flanders & 62537 & 4.9 & 38.5 & 42.7 & 13.9 & 213 & 3.4 & 5.9 & 3.9 & 3.1 & 2.1 \\
\hline BE: Wallonia & 30930 & 9.8 & 36.4 & 42.2 & 11.5 & 110 & 3.6 & 6.9 & 3.5 & 3.1 & 2.5 \\
\hline Estonia & 12274 & 2.2 & 34.7 & 19.7 & 43.4 & 39 & 3.2 & 0.0 & 3.3 & 3.3 & 3.2 \\
\hline Finland & 52555 & 3.7 & 40.7 & 30.7 & 24.8 & 88 & 1.7 & 0.0 & 1.8 & 2.0 & 1.3 \\
\hline France & 13637 & 4.3 & 37.0 & 40.3 & 18.4 & 70 & 5.1 & 6.9 & 6.7 & 3.5 & 5.2 \\
\hline Ireland & 54906 & 7.1 & 40.1 & 26.1 & 26.7 & 240 & 4.4 & 5.4 & 4.4 & 3.8 & 4.6 \\
\hline Portugal & 90056 & 5.2 & 43.2 & 34.9 & 16.7 & 192 & 2.1 & 6.0 & 2.4 & 1.7 & 1.0 \\
\hline Spain & 448911 & 1.5 & 46.8 & 32.0 & 19.6 & 1193 & 2.7 & 2.9 & 2.9 & 2.6 & 2.3 \\
\hline $\begin{array}{l}\text { UK: England } \\
\text { and Wales }\end{array}$ & 636793 & $N A^{a}$ & 40.2 & 21.2 & 38.6 & 3053 & 4.8 & $N A^{*}$ & 5.5 & 4.7 & 4.1 \\
\hline
\end{tabular}



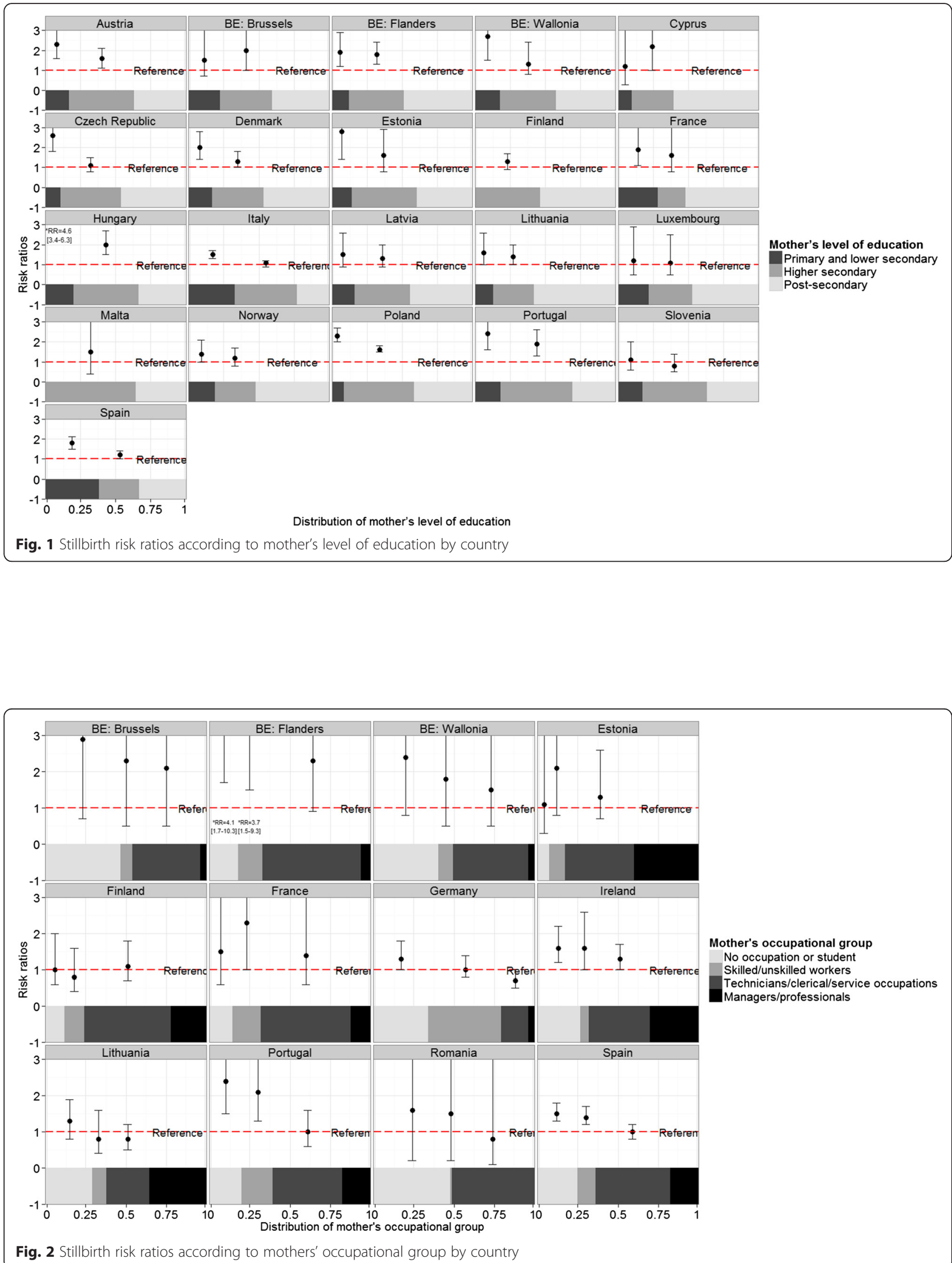


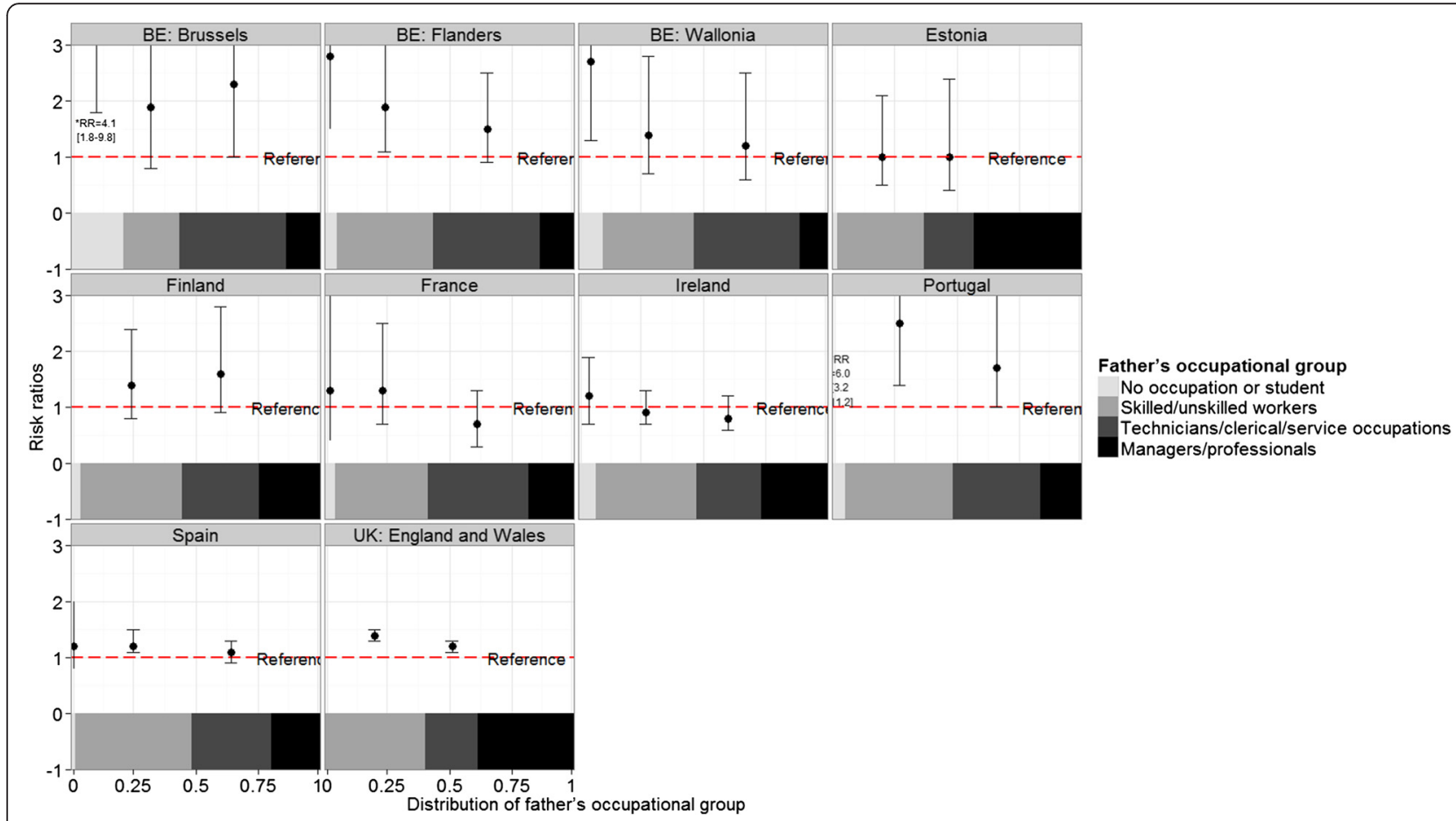

Fig. 3 Stillbirth risk ratios according to father's occupation by country

1.6 (IQR: 1.0-2.1) whereas for father's occupational group, the median RR was 1.4 (IQR: 1.2-1.8). Estimates of RR and $95 \%$ confidence intervals are given in Additional file 1: Tables S2, S3 and S4. The magnitude of the RR for the three socioeconomic variables was not correlated with the percent of missing data (rho statistics and $p$ values presented in Additional file 1).

Table 4 presents \%PAR for each socioeconomic classification by country. This measure assesses the difference between the observed situation and an optimal one in which all pregnant women have the stillbirth risks of the group with the highest educational or occupational level. For mother's level of education, the median \%PAR was 26 (IQR 16 to 31). For Father's and mother's occupational groups, medians (IQR) were 19 (3 to 37 ) and 22 (12 to 37) respectively. When applied to the entire sample with data on mother's level of education, 1606 out of 6337 stillbirths would not have occurred if stillbirth rates for all women were the same as for women with postsecondary education in their country (Fig. 4). For father's occupational groups, 904 of 5304 stillbirths would not have occurred if all groups had the same stillbirth rates as professionals and managers while using mother's occupational groups in the same way, 861 out of 4901 would not have occurred.

\section{Discussion}

Despite the differences in health policies, educational policies and reporting systems across Europe, the available data from routine systems about stillbirths by socioeconomic status pointed to widespread and consistent socioeconomic inequalities in the stillbirth rate. Over three quarters of 29 participating European countries provided data on stillbirths by either mothers' educational levels or parents' occupation. While data about mothers' educational levels were more widely available and comparable than data about mothers' or fathers' occupations, some of the larger countries, notably Germany and England and Wales combined only had data by parents' occupations. Among countries with data, the median RR for stillbirth was 1.9 for women with primary or lower secondary education and 1.4 for those the intermediate category of higher secondary education compared to women with post-secondary education.. Median RR in the lowest occupational categories compared to highest were 1.6 and 1.4, respectively, for mothers' and fathers' occupational groups. These differences had substantial impacts at a population-level: if all women faced the stillbirth risks of the most educated, the number of stillbirths would be $25 \%$ lower.

The main strength of our study is the ability to present data from all over Europe collected for the same year 
Table 4 Population attributable risk (PAR) percentage by country

\begin{tabular}{|c|c|c|c|c|c|c|}
\hline \multirow[t]{2}{*}{ Country } & \multicolumn{2}{|c|}{ Education } & \multicolumn{2}{|c|}{ Maternal occupation } & \multicolumn{2}{|c|}{ Paternal occupation } \\
\hline & $\%$ PAR & $95 \%$ Cl & $\%$ PAR & $95 \%$ Cl & $\%$ PAR & $95 \% \mathrm{Cl}$ \\
\hline Austria & 32 & $15-46$ & & & & \\
\hline BE: Brussels & 33 & $-9-58$ & 59 & $-63-90$ & 59 & $10-81$ \\
\hline BE: Flanders & 29 & $13-42$ & 64 & $14-85$ & 39 & $5-61$ \\
\hline BE: Wallonia & 31 & $1-51$ & 46 & $-65-82$ & 29 & $-33-62$ \\
\hline Cyprus & 27 & $-13-53$ & & & & \\
\hline Czech Republic & 17 & $1-31$ & & & & \\
\hline Denmark & 22 & $7-35$ & & & & \\
\hline Estonia & 34 & $-1-56$ & 20 & $-23-48$ & 0 & $-44-30$ \\
\hline Finland & 11 & $-5-24$ & 5 & $-33-32$ & 22 & $-19-49$ \\
\hline France & 27 & $0-47$ & 34 & $-34-68$ & -1 & $-65-38$ \\
\hline Germany & & & 7 & $-22-29$ & & \\
\hline Hungary & 54 & $41-64$ & & & & \\
\hline Ireland & & & 24 & $7-37$ & -6 & $-30-13$ \\
\hline Italy & 15 & $6-24$ & & & & \\
\hline Latvia & 17 & $-6-36$ & & & & \\
\hline Lithuania & 16 & $1-30$ & 0 & $-26-20$ & & \\
\hline Luxembourg & 5 & $-42-37$ & & & & \\
\hline Malta & 24 & $-100-71$ & & & & \\
\hline Norway & 12 & $-4-25$ & & & & \\
\hline Poland & 30 & $25-35$ & & & & \\
\hline Portugal & 41 & $22-55$ & 33 & $3-54$ & 53 & $24-71$ \\
\hline Romania & & & 15 & $-499-88$ & & \\
\hline Slovenia ${ }^{a}$ & -7 & $-42-20$ & & & & \\
\hline Spain & 26 & $17-33$ & 14 & $2-25$ & 13 & $2-24$ \\
\hline UK: England and Wales & & & & & 15 & $11-19$ \\
\hline
\end{tabular}

${ }^{a}$ Terminations of pregnancy removed for Slovenia

using a standardised instrument. We also requested data about mothers' educational levels using local classifications and mapped these to the ISCED-97 classification to ensure consistency in coding and then checked our coded data with the data providers in each country. Our study also has several limitations. Because we used aggregated data, we were unable to explore the contribution of other demographic or behavioural factors, such as maternal age, parity, migrant status, smoking or body mass index to the higher risks associated with our socioeconomic indicators. Further, even though Euro-Peristat uses a common inclusion threshold of 22 weeks of gestation for births and deaths, not all countries are able to provide these data and even when they can, practices related to recording of early stillbirths differ [19]. While it is likely that these differences relate primarily to legislation and recording practices and not women's socioeconomic circumstances, social inequalities may be more acute for early stillbirths and underreporting might thus affect the comparability between countries [5]. For countries where TOP cannot be differentiated from spontaneous stillbirths, the social gradient may be attenuated as TOP reflect the prevalence of anomalies for which the social gradient is less consistent [23, 24] as well as access to prenatal screening, which may have an inverse gradient in some countries [25]. Finally, some countries had missing data on socioeconomic factors which could bias the estimates. This bias likely leads to underestimates of the effects as missing data were more frequent among stillbirths and may also be more frequent for socially disadvantaged and migrant women.[26]

Because there are no universal measures of social disadvantage, researchers use a wide variety of different indicators: occupation, education, income, other measures of wealth, housing conditions, lack of access to health care, in particular prenatal care, and others. We used two indicators selected in a Delphi process based on assessments of importance and feasibility. The definition of these indicators, level of education 


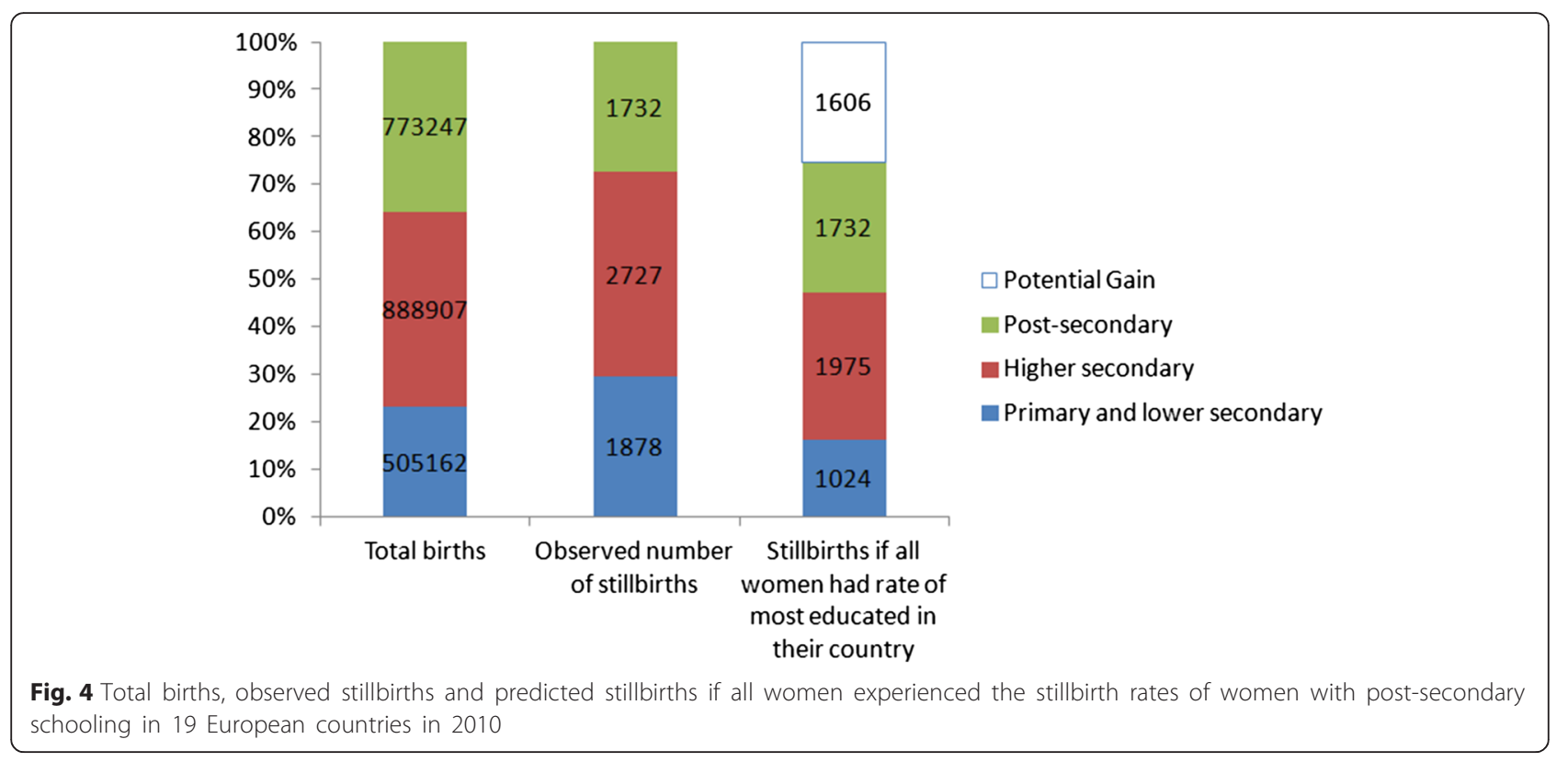

and occupational group, were based on common classifications agreed upon by international organizations. However, categories may not reflect similar constructs in all countries or be understood in the same manner by responders or coders.

For mothers' educational level, comparability issues related to the limit for differentiating between lower and higher secondary schooling, to the classification of vocational tracts and to the inclusion of a category for no or limited schooling, which may be relevant for some migrant women There are also real differences in educational attainment across Europe. Similarly broad variations in maternal education have been documented in comparative studies based on birth cohorts across Europe [27, 28]. However, despite the differences in the distribution of maternal educational attainment a negative social gradient was observed in most countries when this indicator was used.

For mothers' and father' occupation, questions of comparability were more complex as it was not possible to describe original data. Rules for recording and classifying occupations for parents who are not in paid employment or seeking work at the time their babies are born and lone mothers registering births without the involvement of the babies' fathers were not clear. Compared to mothers' educational level, there was higher variation in the distribution of categories between countries, RR tended to be lower and did not always follow a linear gradient. Furthermore, while the ISCO classification appeared to be widely used, there are questions about whether a status based classification of occupations is most relevant. Some research suggests that a classification based on employment relations (i.e. employers, employees or self-employed) provides more useful insights into the nature of social inequalities and their potential impact of health $[29,30]$ and these principles have been used for the development of a European Classification [31]. Given these conceptual and practical difficulties, one way of improving comparisons across countries would be to promote the recording of mothers' educational level in routine systems either directly or through data linkage.

Studies from other high-income countries have documented elevated risks of similar magnitude for women with low socioeconomic position. For instance, using Canadian data, Auger et al. reported relative risks of 1.6 and 1.3 for low and intermediate educational levels compared with women with the highest educational level [5]. In a large US case control study, the unadjusted OR for educational level were 1.5 and 1.4, respectively for women with primary or some secondary and completed secondary compared to women with a post-secondary education [32]. The reasons for these elevated risks are likely multiple and interconnected. One UK study investigating stillbirths by area-based deprivation scores found that deprivation gaps existed for all causes, except for mechanical events, with the widest gap for stillbirths due to antepartum haemorrhages [3]. The study in Canada found differences throughout the gestational age spectrum, although they were more marked at earlier gestational ages [5].

The finding that social factors are not restricted to specific causes or gestational age groups is not surprising. Many risk factors, including smoking, diet and healthcare factors, affect a number of pregnancy complications such as extremely preterm delivery, growth restriction and congenital anomalies which raise stillbirth risk and are more common among less advantaged 
groups in the population. Mothers in these groups are more likely to have high body mass indices (BMI) and to smoke during pregnancy and these are important risk factors for stillbirth [33]. Other risk factors, such as migrant status, also affect a wide range of reproductive health outcomes [34, 35]. Social differences in screening and termination of pregnancy may also play a role if socially disadvantaged women are less likely to terminate pregnancies with lethal anomalies, either because of lack of access to screening or differences in attitudes to pregnancy terminations $[24,25,36]$. Antenatal detection of growth restriction may play a role in preventing stillbirth and the extent to which social position affects access to screening should also be considered [37]. The question of how much of the social gradient is explained by these behavioural and healthcare factors, especially those that are potentially modifiable, is an important area for further research.

While we found consistent associations between risks of stillbirth and social factors in European countries, the magnitude of the social gradient varied. Some of this variation could be related to small sample sizes in some countries as well as to the non-comparability of socioeconomic classifications. However, studies comparing the Nordic countries have found differences in the social gradient of stillbirth risk even within these relatively homogenous societies [2]. Other studies of socioeconomic inequalities in Europe have uncovered differences in the inequality gradient for overall mortality rates which are partially correlated with differences in the prevalence of smoking and overweight in the population [38]. Other European studies have also suggested that healthcare can contribute to differences in outcomes, for instance in cancer mortality, which may reflect social inequalities in access and quality of care [39]. In the perinatal field, this is an important area for further investigation and could be a powerful tool for identifying population-based risk factors and health care policies that contribute to stillbirth etiology and thereby to prevention of stillbirth for the benefit of all women.

\section{Conclusion}

This study documented widespread social inequalities in stillbirth risk in Europe, revealing the extent to which stillbirth can be a consequence of social disadvantage. While more research is needed to better understand differences in the magnitude of these differences between countries and how to harmonise use of socioeconomic categories, available data in routine systems can be used to set goals for the future and to monitor changes over time.

\section{Availability of data and materials}

Data used in this analysis can be requested from the Euro-Peristat coordination team through the project's website (www.europeristat.com).

\section{Additional file}

Additional file 1: Table S1. Inclusion criteria for stillbirths. Table S2. Stillbirth risk ratios according to maternal education by country. Table S3. Stillbirth risk ratios according to maternal occupation by country. Table S4. Stillbirth risk ratios according to paternal occupation by country. (DOCX 37 kb)

\section{Competing interests}

The authors declare that they have no competing interests.

\section{Authors' contributions}

JZ had full access to all of the data in the study and take responsibility for the integrity of the data and the accuracy of the data analysis. Study concept and design: JZ, LM, CP, AM, ADH-M, MG, KVP, KS, FB, AMNA, HSO, $\mathrm{WHZ}, \mathrm{BB}$; Acquisition, analysis, or interpretation of data: All authors, including authors in the Euro-Peristat SC (GH, PP, PV, LS, NL, AA, IB,SB, MC, JM, JJ, YW, $M G, J N, K K, H B, M H, J C, N T M, K G, S B$ ); Drafting of the manuscript: JZ, LM, CP, AM, ADH-M, MG, KVP, KS, FB, AMNA, HSO, WHZ, BB, SA Critical revision of the manuscript for important intellectual content and approval of final version of the manuscript: All authors, including authors listed in Euro-Peristat SC $(G H, P P, P V, L S, N L, A A, I B, S B, M C, J M, J J, Y W, M G, J N, K K, H B, M H, J C, N T M$, KG, SB); Statistical analysis: CP, JZ, LM; Study supervision: JZ, LM, BB, SA; Obtained funding: JZ, AM, AHM, KVP, BB, KS, SA.

\section{Acknowledgements}

The authors acknowledge the following contributors to the European Perinatal Health Report: Health and Care of Pregnant Women and Babies in Europe in 2010:

Austria, Gerald Haidinger, The Medical University of Vienna, Department of Epidemiology, Centre of Public Health; Jeannette Klimont, Statistics Austria; Belgium, Sophie Alexander, Wei-Hong Zhang, Michèle Dramaix-Wilmet, Mélissa Van Humbeeck, Université Libre de Bruxelles, School of Public Health, Epidemiology, Biostatistics and Clinical Research Centre; Charlotte Leroy, Anne-Frédérique Minsart, Virginie van Leeuw, Centre d'Epidémiologie Périnatale (Cepip); Evelyne Martens, SPE (Study Center for Perinatal Epidemiology); Myriam De Spiegelaere, Brussels Health and Social Observatory, Freddy Verkruyssen, Michel Willems, FPS Economy, SMEs, Self-employed and Energy; Willem Aelvoet, The Federal Public Service (FPS) Health, Food Chain Safety and Environment; Jean Tafforeau, Francoise Renard, Denise Walckiers, Focal Point for the data collection on national health statistics for Eurostat, OECD and WHO; Deborah Cuignet, Philippe Demoulin, French Community of Belgium; Heidi Cloots, Erik Hendrickx, Anne Kongs, Flemish Agency for Care and Health; Cyprus, Pavlos Pavlou, Despina Stylianou, Theopisti Kyprianou, Ministry of Health, Health Monitoring Unit; Nicos Skordes, Pediatric Department, Makarios III Hospital; Czech Republic, Petr Velebil, Institute for the Care of Mother and Child; Denmark, Jens Langhoff Roos, Obstetrics Clinic, Rigshospitalet, Copenhagen University; Anne-Marie Nybo Anderson, Laust Hvas Mortensen, University of Copenhagen; Estonia, Luule Sakkeus, Estonian Institute for Population Studies, Tallinn University; Finland, Mika Gissler, Anna Heino, Annukka Ritvanen, THL National Institute for Health and Welfare, Health Services Department; France, Béatrice Blondel, Marie-Hélène Bouvier Colle, Marie Delnord, Jennifer Zeitlin, National Institute of Health and Medical Research (INSERM) U1153; Anne Ego, RHEOP Register for Disabled Children and Perinatal Observatory; Grégoire Rey, National Center of Statistics for Medical Causes of Death (CépiDc), National Institute of Health and Medical Research (INSERM); Germany, Nicholas Lack, Bavarian Institute for Quality Assurance; Guenther Heller, AQUA-Institut; Anton Scharl, Department of Obstetrics and Gynaecology; Klinikum Amberg; Greece, Aris Antsaklis, Peter Drakakis, Athens University Medical School, Athens; Hungary, István Berbik, Department of Obstetrics and Gynaecology, Vaszary Kolos Teaching Hospital; Iceland, Helga Sól Ólafsdóttir, Ragnheiður I. Bjarnadottir, Hildur Harðardóttir, Brynja Ragnarsdóttir, Vigdís Stefánsdóttir Landspitali University Hospital; Sigríður Haraldsdóttir, Landlaeknis Directorate of Health; Ireland, Sheelagh Bonham, Aisling Mulligan, The Economic and Social Research Institute (ESRI), Heath Research \& Information Division; Italy, Marina Cuttini, Pediatric Hospital of Baby Jesus, Unit of Epidemiology; Cristina Tamburini, Rosaria Boldrini, General Directorate for the Health Information and Statistical System, Italian Ministry of Health; Sabrina Prati, Marzia Loghi, Cinzia Castagnaro, Stefano Marchetti, Alessandra Burgio, Central Directorate for Socio-demographic and Environmental Statistics, Italian National Institute for Statistics-ISTAT; Monica Da Frè, Epidemiology Observatory, Regional Agency for Health of Tuscany 
Latvia, Janis Misins, Irisa Zile, The Centre for Disease Prevention and Control of Latvia; Lithuania, Jelena Isakova, Rita Gaidelyte, Jone Jaselione, Institute of Hygiene, Health information centre; Luxembourg, Yolande Wagener, Guy Weber Ministry of Health, Department of Health, Division of Preventive and Social Medicine; Audrey Billy, Aline Touvrey-Lecomte, Public Health Research Center; Malta, Miriam Gatt, Dept of Health Information and Research, National,Obstetric Information Systems (NOIS) Register,; Netherlands, Jan Nijhuis, Maastricht University Medical Center, Department of Obstetrics \& Gynecology, Maastricht; Karin van der Pal de Bruin and Ashna Hindori-Mohangoo, TNO Healthy Living, Department Child Health, Leiden; Peter Achterberg, National Institute for Public Health and the Environment; Chantal Hukkelhoven and Ger de Winter, The Netherlands Perinatal Registry; Anita Ravelli, Academic Medical Research Center; Greta Rijninks-van Driel, The Royal Dutch College of Midwives; Pieter Tamminga, Paediatric Association of the Netherlands; Martin Groesz, Perinatal Audit Netherlands; Patty Elferink-Stinkens, Statistics Netherlands; Norway, Kari Klungsoyr, Medical Birth Registry of Norway, Norwegian Institute of Public Health and Department of Global Public Health and Primary Care, University of Bergen; Arild Osen, Marta Ebbing, Medical Birth Registry of Norway, The Norwegian Institute of Public Health; Poland, Katarzyna Szamotulska, National Research Institute of Mother and Child, Department of Epidemiology and Biostatistics with collaboration from The Central Statistical Office, the National Health Fund and Ministry of Health; Portugal, Henrique Barros, Sofia Correia, University of Porto Medical School, Department of Clinical Epidemiology, Predictive Medicine and Public Health; Institute of Public Health; Romania, Mihai Horga, Senior Advisor at the East European Institute for Reproductive Health, East European Institute for Reproductive Health; Alexandra Cucu, National Institute of Public Health; Slovakia, Jan Cap, National Health Information Center; Slovenia, Živa Novak-Antolič, University Medical Centre, Perinatology Unit, Ljubljana University; Ivan Verdenik, University Medical Centre, Department of Obstetrics\& Gynecology, Research Unit; Spain, Francisco Bolumar, Alcala University Medical School; Mireia Jané, Maria José Vidal, Public Health Surveillance Direction, Catalan Public Health Agency; Carmen Barona, Rosa Mas, Public Health, Generalitat Valenciana; Adela Recio Alcaide, National Institute for Statistics (INE); Sweden, Karin Gottvall, Ellen Lundqvist, The National Board of Health and Welfare, Department of Statistics, Monitoring and Evaluation, Statistics on Public Health and Social Care Unit; Switzerland, Sylvie Berrut, Swiss Federal Statistical Office, Section Health; Claudia König, Monika Schmid, Institut für Hebammen, ZHAW Zürcher, Hochschule für Angewandet Wissenschaften; United Kingdom, Alison Macfarlane, Nirupa Dattani, City University London; Jim Chalmers (now retired), Kirsten Monteath, Information Services Division, NHS National Services Scotland; Marie Climson, National Records of Scotland; Leslie Marr, Healthcare Improvement Scotland; Rod Gibson, Birthchoice UK; Gwyneth Thomas, Rhian Osborne, Health Statistics and Analysis Unit, Welsh Government; Russell Brown, NHS Wales Informatics Service; David Sweet, Joanne Evans, Office for National Statistics; Sinead Magill, Adele Graham, Heather Reid, Public Health Agency; Terry Falconer, Karen McConnell, Northern Ireland Maternal and Child Health, Public Health Agency (now retired); Neil McComb, Human Fertilisation and Embryology Authority.

The Euro-Peristat Scientific Committee: Gerald Haidinger (Austria), Sophie Alexander (Belgium), Pavlos Pavlou (Cyprus), Petr Velebil (Czech Republic), Laust Mortensen (Denmark), Luule Sakkeus (Estonia), Mika Gissler (Finland), Béatrice Blondel (France), Marie Delnord (Project Coordination, France), Jennifer Zeitlin (Project Leader, France) Nicholas Lack (Germany), Aris Antsaklis (Greece), István Berbik (Hungary), Helga Sól Ólafsdóttir (Iceland), Sheelagh Bonham (Ireland), Marina Cuttini (Italy), Janis Misins (Latvia), Jone Jaselioniene (Lithuania), Yolande Wagener (Luxembourg), Miriam Gatt (Malta), Jan Nijhuis (Netherlands), Ashna Hindori-Mohangoo (Project Coordination, Netherlands) Karin van der Pal (Executive board member, Netherlands), Kari Klungsoyr (Norway), Katarzyna Szamotulska (Poland), Henrique Barros (Portugal), Mihai Horga (Romania), Jan Cap (Slovakia), Natasa Tul Mandić (Slovenia), Francisco Bolúmar (Spain), Karin Gottvall (Sweden), Sylvie Berrut (Switzerland), Alison Macfarlane (United Kingdom).

\section{Funding}

The results from this study are based on data from the Euro-Peristat project, a European project for monitoring and evaluating perinatal outcomes on the European level. The Euro-Peristat project received funding from the European Union in the framework of the Health Programme (grant numbers: 20101301 and 664691). The funding agency was not involved in the study. This study used aggregated national indicators, ethical approval was not required.

\section{Author details}

'Inserm UMR 1153, Obstetrical, Perinatal and Pediatric Epidemiology Research Team (Epopé), Center for Epidemiology and Statistics Sorbonne Paris Cité, DHU Risks in pregnancy, Paris Descartes University, 53 avenue de I'Observatoire, 75014 Paris, France. ${ }^{2}$ Department of Public Health, University of Copenhagen, Copenhagen, Denmark. ${ }^{3}$ Centre for Maternal and Child Health Research, City University London, London, England. ${ }^{4}$ Department of Child Health, TNO, Netherlands Organisation for Applied Scientific Research, Leiden, The Netherlands. ${ }^{5}$ THL National Institute for Health and Welfare, Helsinki, Finland. ${ }^{6}$ Department of Epidemiology, National Research Institute of Mother and Child, Kasprzaka 17 a, 01-211 Warsaw, Poland. ${ }^{7}$ Department of Public Health Sciences, University of Alcalá, Madrid, Spain. ${ }^{8}$ Department of Obstetrics and Gynaecology, Landspitali University Hospital, Landspitali v/ Hringbraut, Reykjavík, Iceland. ${ }^{9}$ Perinatal Epidemiology and Reproductive Health Unit, Epidemiology, Biostatistics and Clinical Research Centre, School of Public Health, Université Libre de Bruxelles, Brussels, Belgium.

Received: 1 July 2015 Accepted: 8 January 2016

Published online: 19 January 2016

\section{References}

1. Flenady V, Koopmans L, Middleton P, Froen JF, Smith GC, Gibbons K, et al. Major risk factors for stillbirth in high-income countries: a systematic review and meta-analysis. Lancet. 2011;377(9774):1331-40.

2. Rom AL, Mortensen LH, Cnattingius S, Arntzen A, Gissler M, Andersen AM. A comparative study of educational inequality in the risk of stillbirth in Denmark, Finland, Norway and Sweden 1981-2000. J Epidemiol Community Health. 2012;66(3):240-6.

3. Seaton SE, Field DJ, Draper ES, Manktelow BN, Smith GC, springett A, et al. Socioeconomic inequalities in the rate of stillbirths by cause: a population-based study. BMJ Open 2012, 2(3). doi: 10.1136/bmjopen2012-001100. Print 2012

4. Wood AM, Pasupathy D, Pell JP, Fleming M, Smith GC. Trends in socioeconomic inequalities in risk of sudden infant death syndrome, other causes of infant mortality, and stillbirth in Scotland: population based study. BMJ. 2012;344:e1552.

5. Auger N, Delezire P, Harper S, Platt RW. Maternal education and stillbirth: estimating gestational-age-specific and cause-specific associations. Epidemiology. 2012;23(2):247-54.

6. Jorgensen T, Mortensen LH, Andersen AM. Social inequality in fetal and perinatal mortality in the Nordic countries. Scand J Public Health. 2008;36(6): 635-49.

7. Goy J, Dodds L, Rosenberg MW, King WD. Health-risk behaviours: examining social disparities in the occurrence of stillbirth. Paediatr Perinat Epidemiol. 2008;22(4):314-20.

8. Aune D, Saugstad OD, Henriksen T, Tonstad S. Maternal body mass index and the risk of fetal death, stillbirth, and infant death: a systematic review and meta-analysis. JAMA. 2014;311(15):1536-46.

9. Kramer MS, Seguin L, Lydon J, Goulet L. Socio-economic disparities in pregnancy outcome: why do the poor fare so poorly? Paediatr Perinat Epidemiol. 2000;14(3):194-210.

10. Stillbirth Collaborative Research Network Writing G. Causes of death among stillbirths. JAMA. 2011;306(22):2459-68.

11. Helgadottir LB, Turowski G, Skjeldestad FE, Jacobsen AF, Sandset PM, Roald $B$, et al. Classification of stillbirths and risk factors by cause of death-a casecontrol study. Acta Obstet Gynecol Scand. 2013;92(3):325-33.

12. Flenady V, Middleton P, Smith GC, Duke W, Erwich JJ, Khong TY, et al. Stillbirths: the way forward in high-income countries. Lancet. 2011; 377(9778):1703-17.

13. Hogue CJ, Parker CB, Willinger M, Temple JR, Bann CM, Silver RM, et al. The association of stillbirth with depressive symptoms $6-36$ months postdelivery. Paediatr Perinat Epidemiol. 2015;29(2):131-43.

14. Hvidtjorn D, Wu C, Schendel D, Thorlund Parner E, Brink Henriksen T. Mortality in mothers after perinatal loss: a population-based follow-up study. BJOG. doi: 10.1111/1471-0528.13268. [Epub ahead of print]

15. Gissler M, Mohangoo AD, Blondel B, Chalmers J, Macfarlane A, Gaizauskiene $A$, et al. Perinatal health monitoring in Europe: results from the EUROPERISTAT project. Inform Health Soc Care. 2010;35(2):64-79.

16. Zeitlin J, Mohangoo AD, Delnord M, Cuttini M, Committee E-PS. The second European Perinatal Health Report: documenting changes over 6 years in the 
health of mothers and babies in Europe. J Epidemiol Community Health. 2013;67(12):983-5.

17. Euro-Peristat project with SCPE and EUROCAT. European Perinatal Health Report. The Health and Care of pregnant women and babies in Europe in 2010. In: J. Zeitlin, M. Delnord, A Mohangoo, eds; 2013.

18. Zeitlin J, Wildman K, Breart G, Alexander S, Barros H, Blondel B, et al. Selecting an indicator set for monitoring and evaluating perinatal health in Europe: criteria, methods and results from the PERISTAT project. Eur J Obstet Gynecol Reprod Biol. 2003;111 Suppl 1:S5-14.

19. Mohangoo AD, Buitendijk SE, Szamotulska K, Chalmers J, Irgens LM, Bolumar F, et al. Gestational age patterns of fetal and neonatal mortality in europe: results from the Euro-Peristat project. PLOS ONE. 2011;6(11):e24727.

20. Fresson J, Blondel B. Stillbirths soon to emerge from statistical limbo in France. J Gynecol Obstet Biol Reprod. 2013;42(1):1-4

21. United National Educational Scientific and Cultural Organisation. nternational Standard Classification of Eduction (ISCED) 1997. In.; 2006 http://www.uis.unesco.org/Library/Documents/isced97-en.pdf (accessed 30/06/2015)

22. Rose D, O'Reilly K. The ESRC Review of Government Social Classification. Swindon: ESRC \& ONS; 1998.

23. Vrijheid M, Dolk H, Stone D, Abramsky L, Alberman E, Scott JE. Socioeconomic inequalities in risk of congenital anomaly. Arch Dis Child. 2000;82(5):349-52.

24. Smith LK, Budd JL, Field DJ, Draper ES. Socioeconomic inequalities in outcome of pregnancy and neonatal mortality associated with congenital anomalies: population based study. BMJ. 2011;343:d4306.

25. Khoshnood B, De Vigan C, Blondel B, Vodovar V, Cadio E, Goffinet F. Long-term trends for socio-economic differences in prenatal diagnosis of Down syndrome: diffusion of services or persistence of disparities? BJOG. 2008;115(9):1087-95.

26. Minsart AF, Buekens P, De Spiegelaere M, Van de Putte S, Van Leeuw V, Englert Y. Missing information in birth certificates in Brussels after reinforcement of data collection, and variation according to immigration status. A population-based study. Archives of Public Health $=$ Archives belges de sante publique. 2012;70(1):25.

27. Poulsen G, Strandberg-Larsen K, Mortensen L, Barros H, Cordier S, Correia S, et al. Exploring educational disparities in risk of preterm delivery: a comparative study of 12 European birth cohorts. Paediatr Perinat Epidemiol. 2015;29(3):172-83.

28. Ruiz M, Goldblatt P, Morrison J, Kukla L, Svancara J, Riitta-Jarvelin M, et al. Mother's education and the risk of preterm and small for gestational age birth: a DRIVERS meta-analysis of 12 European cohorts. J Epidemiol Community Health. 2015;69(9):826-33.

29. Rose D, Pevalin DJ, O'Reilly K. The National Statistics Socio-economic Classification: Origins, Development and Use. Basingstoke: Palgrave Macmillan; 2005.

30. Office for National Statistics. A combined approach to National Statistics socio-economic classification. In.; 2013 http://www.ons.gov.uk/ons/guidemethod/user-guidance/health-and-life-events/a-combined-approach-tonational-statistics-socio-economic-classification/index.html (accessed 21/ 06/205).

31. Rose D, Harrison E. The European Socio-economic Classification: A New Social Class Schema for European Research. Eur Soc. 2007;9(3):459-90.

32. Stillbirth Collaborative Research Network Writing G. Association between stillbirth and risk factors known at pregnancy confirmation. JAMA. 2011; 306(22):2469-79.

33. Chu SY, Kim SY, Lau J, Schmid CH, Dietz PM, Callaghan WM, et al. Materna obesity and risk of stillbirth: a metaanalysis. Am J Obstet Gynecol. 2007; 197(3):223-8.

34. Gissler M, Alexander S, MacFarlane A, Small R, Stray-Pedersen B, Zeitlin J, et al. Stillbirths and infant deaths among migrants in industrialized countries. Acta Obstet Gynecol Scand. 2009;88(2):134-48.

35. Gagnon AJ, Zimbeck M, Zeitlin J, Alexander S, Blondel B, Buitendijk S, et al. Migration to western industrialised countries and perinatal health: a systematic review. Soc Sci Med. 2009;69(6):934-46.

36. Tararbit K, Bui TT, Lelong N, Thieulin AC, Goffinet F, Khoshnood B. Clinical and socioeconomic predictors of pregnancy termination for fetuses with congenital heart defects: a population-based evaluation. Prenat Diagn. 2013; 33(2):179-86.
37. Gardosi J, Madurasinghe V, Williams M, Malik A, Francis A. Maternal and fetal risk factors for stillbirth: population based study. BMJ. 2013;346:f108.

38. Mackenbach JP, Stirbu I, Roskam AJ, Schaap MM, Menvielle G, Leinsalu M, et al. Socioeconomic inequalities in health in 22 European countries. N Engl J Med. 2008;358(23):2468-81.

39. De Angelis R, Sant M, Coleman MP, Francisci S, Baili P, Pierannunzio D, et al. Cancer survival in Europe 1999-2007 by country and age: results of EUROCARE-5-a population-based study. Lancet Oncol. 2014;15(1):23-34

\section{Submit your next manuscript to BioMed Central and we will help you at every step:}

- We accept pre-submission inquiries

- Our selector tool helps you to find the most relevant journal

- We provide round the clock customer support

- Convenient online submission

- Thorough peer review

- Inclusion in PubMed and all major indexing services

- Maximum visibility for your research

Submit your manuscript at www.biomedcentral.com/submit
( ) BioMed Central 